\title{
Preliminary Observations of Some Paleopathological Conditions in Historic and Modern Human Skeletal Remains from Ishigaki Island, Ryukyu Islands, Japan
}

\author{
Chosei Zukeran ${ }^{1}$, Tadahiko Fukumine ${ }^{1}$, Naomi Doi ${ }^{1}$, Noburu Sensui ${ }^{1}$, \\ Hajime Ishida $^{1}$, Fuminori Kanaya ${ }^{2}$, and Ayano Shimabukuro ${ }^{3}$ \\ ${ }^{1}$ Department of Anatomy, Faculty of Medicine, University of the Ryukyus, Okinawa \\ ${ }^{2}$ Department of Orthopedics, Faculty of Medicine, University of the Ryukyus, Okinawa \\ ${ }^{3}$ Civic History Compilation Division, General Affairs Department, Ishigaki City Hall, Okinawa
}

(Received November 2, 2001; accepted July 25, 2002)

\begin{abstract}
This study investigates some aspects of skeletal and dental paleopathology, including cribra orbitalia, dental enamel hypoplasia, trauma, osteoarthritis, periostitis and osteomyelitis. The sample consists of the skeletal remains of 33 individuals from the medieval and early modern periods, found on Ishigaki Island, Ryukyu Islands, Japan. High frequencies of cribra orbitalia and enamel hypoplasias suggest that the Ishigaki people may have experienced many severe nutritional deficiency stresses, infectious diseases, and/or parasitism during early childhood. This study further reports a markedly high frequency of periostitis and two cases of osteomyelitis in bones of the lower leg, probably the result of a specific infection, such as treponematosis.
\end{abstract}

Keywords: paleopathology, cribra orbitalia, dental enamel hypoplasia, osteoarthritis, Ishigaki Island

\section{Introduction}

Prehistoric human occupation of the southernmost part of the Ryukyu Islands has been known since the discovery, in 1900, of the Shimotabaru shellmound, dated at about 3,000 BP, on Hateruma Island of the Yaeyama Islands (Naito, 1986). However, there are very few prehistoric human skeletal remains, that might help elucidate the origins of the present day inhabitants of the Japanese Archipelago. Recently, a number of human skeletal remains were excavated at several medieval and early modern sites on Ishigaki Island of the Yaeyama Island group (Doi and Hojo, 1997). This study represents a preliminary investigation of some paleopathological observations recorded in these remains, which are used to reconstruct some aspects of the lives of these historic inhabitants.

Corresponding author: Hajime Ishida

Department of Anatomy, Faculty of Medicine, University of the Ryukyus

Uehara 207, Nishihara, Okinawa Prefecture 903-0215, Japan

E-mail: ishidaha@med.u-ryukyu.ac.jp 


\section{Materials and Methods}

A summary of the skeletal materials used in this study is given in Table 1. The locations of these skeletal series are shown in Fig. 1. The human remains of the Kuramoto-Ato, Tonoshiro-Nakanuhaka and Arakawa sites date to the 15-16 century A.D. and were mainly buried in individual pits. The Kuramoto-Ato and TonoshiroNakanuhaka sites are located in the same sand dune. A single skeleton was recovered from an individual pit at the Arakawa site. The skeletal remains of the early modern sites, including the Nosoko and Kabira, are from more mixed mortuary contexts including secondary bundle burials in rock shelters (Nosoko 1) or in stonebrick graves (Nosoko 2, Kabira 1 and 2). The human skeleton from the Isobe site was accidentally found during construction work, which has been dated to the 15-16 century A.D. Except for Kuramoto-ato (Doi and Hojo, 1997), no archaeological reports have yet been published for these sites.

The minimum number of individuals was determined using cranial and long limb bone remains. Age at death and sex of these remains are given in Table 2. Sex was estimated using the standards used by Brothwell (1981). However, sex of fragmentary skeletal remains was estimated using the standards proposed by Nakahashi and Nagai (1986). Sex determination of immature skeletal remains was not attempted. Age was primarily estimated using the methods of Miles (1963) and Knussman (1988). Due to the incomplete nature of these remains, many of the adult specimens could not be aged more accurately than simply as "adult."

Macroscopic and radiographic examination of teeth and bones was made in the present study. All expressions of cribra orbitalia (slight, medium, or marked) were recorded as present for each eye socket (Nathan and Hass, 1966; Hirata, 1988a). Linear enamel hypoplasias (LEH) in the deciduous and permanent teeth were re-

Table 1. Number of specimens represented in the Ishigaki sample

\begin{tabular}{|c|c|c|c|c|c|c|}
\hline \multirow{2}{*}{ Site* } & \multirow{2}{*}{ Century } & \multicolumn{2}{|c|}{ Adult } & \multicolumn{2}{|c|}{ Immature } & \multirow{2}{*}{ Total } \\
\hline & & Male & Female & Adolescent & Infant & \\
\hline Tonoshiro-Nakanuhaka & 15 th $\sim 16$ th & 4 & & & & 4 \\
\hline Arakawa & 15 th $\sim 16$ th & & 1 & & & 1 \\
\hline Nosoko 1 & 18th $\sim 19$ th & 1 & & 1 & & 2 \\
\hline Nosoko 2 & 17 th $\sim 19$ th & & 1 & & & 1 \\
\hline Kabira 1 & 18 th $\sim 19$ th & 5 & 6 & & & 11 \\
\hline Kabira 2 & 17 th $\sim 19$ th & 1 & 2 & & & 3 \\
\hline Isobe & unknown & 1 & & & & 1 \\
\hline Kuramoto-Ato & 15 th $\sim 16$ th & 3 & 1 & 1 & 5 & 10 \\
\hline Total & & 15 & 11 & 2 & 5 & 33 \\
\hline
\end{tabular}

*Archaeological sites on Ishigaki Island. 


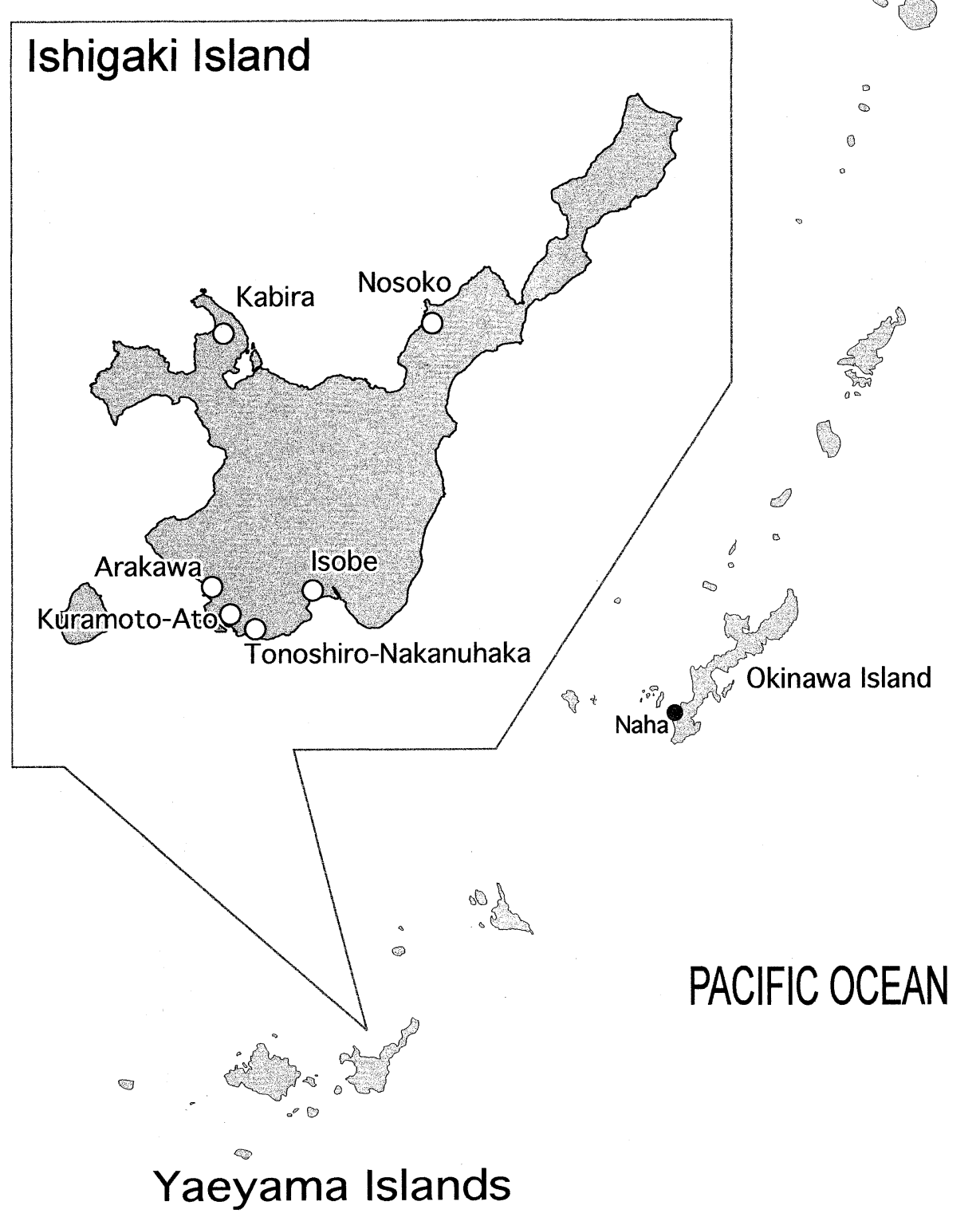

Figure 1. Location of the six archaeological sites on Ishigaki Island from where the human skeletal remains used in this study were recovered. 
Table 2. Age at death and sex of the specimens in the Ishigaki sample

\begin{tabular}{|c|c|c|c|c|c|c|c|}
\hline & $\begin{array}{l}\text { Old } \\
\text { adult }^{1}\end{array}$ & $\begin{array}{c}\text { Middle-aged } \\
\text { adult }^{2}\end{array}$ & $\begin{array}{l}\text { Young } \\
\text { adult }^{3}\end{array}$ & Adult ${ }^{4}$ & $\begin{array}{l}\text { Adoles- } \\
\text { cent }^{5}\end{array}$ & Infant $^{6}$ & Total \\
\hline Male & 4 & 2 & 4 & 5 & & & 15 \\
\hline Female & 2 & 3 & 0 & 6 & & & 11 \\
\hline Unknown & & & & & 2 & 5 & 7 \\
\hline Total & 6 & 5 & 4 & 11 & 2 & 5 & 33 \\
\hline
\end{tabular}

corded for each individual using the methods of Yamamoto (1988). Fuminori Kanaya interpreted the long limb bone fractures using both macroscopic and radiographic examinations. Osteoarthritis was limited to the elbow joint and the bodies of the lumbar vertebrae because of the poor preservation and incompleteness of these remains. Any degenerative osteoarthritic change in the joints was scored as present using the methods of Wada (1975) and Yamaguchi (1984). Because of the incomplete nature of these skeletal remains, the frequencies of these conditions are reported per bone. No statistical tests of significance are performed in this study due to the small sample size.

\section{Results and Discussion}

\section{Cribra orbitalia}

Cribra orbitalia is a defect in the orbital roof, characterized by porotic and trabec-

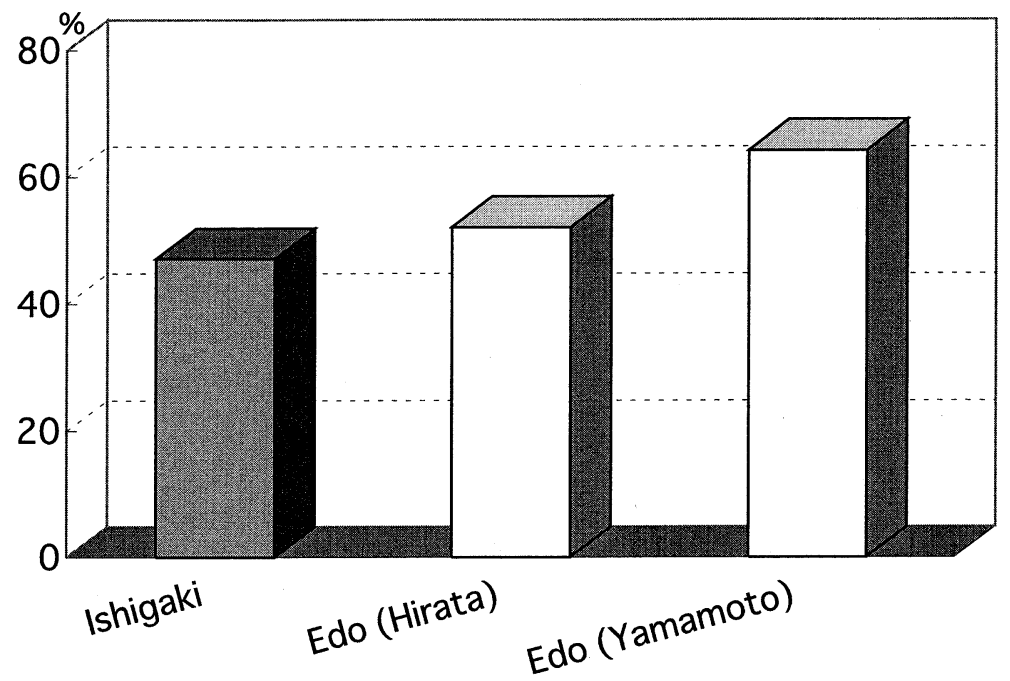

Figure 2. Comparison of the frequencies of cribra orbitalia in adult and immature specimens. Edo (Hirata): Hirata, 1988a, 1988b, 1990; Edo (Yamamoto): Yamamoto, 1988. 
ular lesions (Shultz, 2001). Cribra orbitalia is mainly due to anemic condition followed by chronic and parasitic infections (Fairgrieve and Molto, 2000). The frequency of cribra orbitalia in adult eye sockets is $35.7 \%$ and in the sub-adult eye sockets the frequency is $100.0 \%$ (Table 3 ). Nearly half of the individual eye sockets are affected, and, as reported by other researchers (e.g. Cybulski, 1977; Hirata, 1988a; Salvadei et al., 2001), cribra orbitalia is more frequent in immature eye sockets. Many of the affected skulls also exhibited porotic hyperostosis, which is represented by a thinning of the tables and hypertrophy of the diploë in the cranial vault. The frequency of cribra orbitalia in early modern mainland Japanese specimens is relatively high (52.1\%-64.2\%) (Hirata, 1988a, 1988b, 1990; Yamamoto, 1988), a frequency which is comparable to that reported for the Ishigaki sample (Fig. 2). Hudson (1999), however, reported a lower frequency of cribra orbitalia in the early modern samples from the Ryukyu Islands, which includes skeletal remains from the Okinawa and Kume Islands.

\section{Dental Enamel Hypoplasia}

Linear enamel hypoplasia (LEH) is a developmental defect in the tooth enamel. This dental pathology is caused by a metabolic insult during childhood, including infections and malnutrition (Saunders and Keenleyside, 1999; Lukacs et al., 2001; Robb et al., 2001). The frequency (100\%) of LEH in the Ishigaki remains is high, affecting all the individuals examined (Table 3). Yamamoto $(1988,1992)$ reported the frequencies of dental enamel hypoplasia in the permanent mandibular canines of $65.1 \%$ in the early modern period of mainland Japan and $61.8 \%$ of the Amami Island, Ryukyu Islands (Fig. 3). Although some of the differences in these results may be attributed to interobserver error, the age of these specimens, and which teeth were scored, the high frequency of LEH in the Ishigaki sample requires further investigation using more sophisticated methods such as stable isotope analysis. Likewise, more detailed investigations, including the chronology, duration and severity of hypoplasias will be necessary (e.g. Goodman and Rose, 1990; Larsen, 1997: 43-56;

Table 3. Frequencies of cribra orbitalia (per side) and dental enamel hypoplasia (per individual) in the Ishigaki sample

\begin{tabular}{|c|c|c|c|c|c|c|c|c|c|c|}
\hline & \multicolumn{6}{|c|}{ Adult } & \multirow{2}{*}{\multicolumn{2}{|c|}{ Immature }} & \multirow{2}{*}{\multicolumn{2}{|c|}{ Total }} \\
\hline & \multicolumn{2}{|c|}{ Male } & \multicolumn{2}{|c|}{ Female } & \multicolumn{2}{|c|}{ Total Adult } & & & & \\
\hline & $\mathrm{A}^{1} / \mathrm{O}^{2}$ & $\%$ & $\mathrm{~A} / \mathrm{O}$ & $\%$ & $\mathrm{~A} / \mathrm{O}$ & $\%$ & $\mathrm{~A} / \mathrm{O}$ & $\%$ & $\mathrm{~A} / \mathrm{O}$ & $\%$ \\
\hline Cribra o. (R) & $3 / 9$ & 33.3 & $2 / 5$ & 40.0 & $5 / 14$ & 35.7 & $3 / 3$ & 100.0 & $8 / 17$ & 47.1 \\
\hline Cribra o. (L) & $3 / 9$ & 33.3 & $1 / 5$ & 20.0 & $4 / 14$ & 28.6 & $3 / 3$ & 100.0 & $7 / 17$ & 41.2 \\
\hline Enamel h. ${ }^{3}$ & $9 / 9 \quad 1$ & 100.0 & $5 / 5$ & 100.0 & $14 / 14$ & 100.0 & $7 / 7$ & 100.0 & $21 / 21$ & 100.0 \\
\hline
\end{tabular}

${ }^{1} \mathrm{~A}=$ Affected. ${ }^{2} \mathrm{O}=$ Observed. ${ }^{3}$ Linear enamel hypoplasia recognized in any deciduous or permanent tooth. 


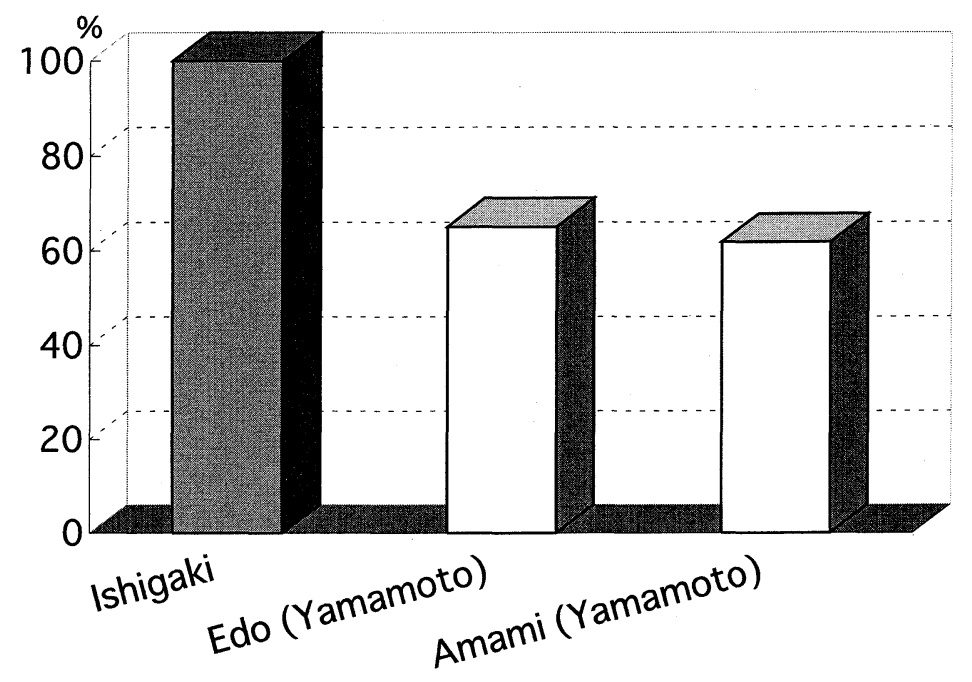

Figure 3. Comparison of the frequencies of dental enamel hypoplasia. Edo (Yamamoto): Yamamoto, 1988, 1992; Amami (Yamamoto): Yamamoto,1988,1992.

Table 4. Frequencies of fractures in the long limb bones based on bones available for study

\begin{tabular}{|c|c|c|c|c|c|c|c|c|c|c|}
\hline & \multicolumn{5}{|c|}{ Adult } & \multirow{2}{*}{\multicolumn{2}{|c|}{ Immature }} & \multirow{2}{*}{\multicolumn{2}{|c|}{ Total }} \\
\hline & & Male & \multicolumn{2}{|c|}{ Female } & \multicolumn{2}{|c|}{ Total Adult } & & & & \\
\hline & & $\mathrm{A}^{1} / \mathrm{O}^{2} \quad \%$ & $\mathrm{~A} / \mathrm{O}$ & $\%$ & $\mathrm{~A} / \mathrm{O}$ & $\%$ & $\mathrm{~A} / \mathrm{O}$ & $\%$ & $\mathrm{~A} / \mathrm{O}$ & $\%$ \\
\hline \multirow[t]{2}{*}{ Clavicle } & (R) & $\begin{array}{ll}0 / 6 & 0.0\end{array}$ & $-/-$ & - & $0 / 6$ & 0.0 & $0 / 1$ & 0.0 & $0 / 7$ & 0.0 \\
\hline & (L) & $0 / 5 \quad 0.0$ & $-1-$ & - & $0 / 5$ & 0.0 & $-1-$ & - & $0 / 5$ & 0.0 \\
\hline \multirow[t]{2}{*}{ Humerus } & $(\mathrm{R})$ & $0 / 6 \quad 0.0$ & $1 / 3$ & 33.3 & $1 / 9$ & 11.1 & $0 / 2$ & 0.0 & $1 / 11$ & 9.1 \\
\hline & $(\mathrm{L})$ & $0 / 6 \quad 0.0$ & $0 / 5$ & 0.0 & $0 / 11$ & 0.0 & $0 / 2$ & 0.0 & $0 / 13$ & 0.0 \\
\hline \multirow[t]{2}{*}{ Ulna } & (R) & $0 / 7 \quad 0.0$ & $0 / 3$ & 0.0 & $0 / 10$ & 0.0 & $0 / 2$ & 0.0 & $0 / 12$ & 0.0 \\
\hline & (L) & $0 / 4 \quad 0.0$ & $0 / 1$ & 0.0 & $0 / 5$ & 0.0 & $0 / 2$ & 0.0 & $0 / 7$ & 0.0 \\
\hline \multirow[t]{2}{*}{ Radius } & (R) & $0 / 7 \quad 0.0$ & $0 / 3$ & 0.0 & $0 / 10$ & 0.0 & $0 / 2$ & 0.0 & $0 / 12$ & 0.0 \\
\hline & (L) & $2 / 6 \quad 33.3$ & $0 / 1$ & 0.0 & $2 / 7$ & 28.6 & $0 / 2$ & 0.0 & $2 / 9$ & 22.2 \\
\hline \multirow[t]{2}{*}{ Femur } & (R) & $0 / 5 \quad 0.0$ & $0 / 5$ & 0.0 & $0 / 10$ & 0.0 & $0 / 2$ & 0.0 & $0 / 12$ & 0.0 \\
\hline & (L) & $0 / 5 \quad 0.0$ & $0 / 4$ & 0.0 & $0 / 9$ & 0.0 & $0 / 2$ & 0.0 & $0 / 11$ & 0.0 \\
\hline \multirow[t]{2}{*}{ Tibia } & (R) & $0 / 6 \quad 0.0$ & $0 / 3$ & 0.0 & $0 / 9$ & 0.0 & $0 / 1$ & 0.0 & $0 / 10$ & 0.0 \\
\hline & (L) & $3 / 8 \quad 37.5$ & $0 / 3$ & 0.0 & $3 / 11$ & 27.3 & $0 / 2$ & 0.0 & $3 / 13$ & 23.1 \\
\hline \multirow[t]{2}{*}{ Fibula } & (R) & $\begin{array}{ll}0 / 6 & 0.0\end{array}$ & $0 / 3$ & 0.0 & $0 / 9$ & 0.0 & $0 / 1$ & 0.0 & $0 / 10$ & 0.0 \\
\hline & (L) & $1 / 6 \quad 16.7$ & $0 / 3$ & 0.0 & $1 / 9$ & 11.1 & $0 / 2$ & 0.0 & $1 / 11$ & 9.1 \\
\hline
\end{tabular}

${ }^{1} \mathrm{~A}=$ Affected. $\quad{ }^{2} \mathrm{O}=$ Observed. 
Kikuchi et al., 2000).

\section{Trauma}

Trauma includes fractures, crushing injuries, dislocations, among others (Steinbock, 1976). Fractures are indicators of cultural behavior as well as accidents. A summary of the healed fractures in the long limb bones in the Ishigaki series is given in Table 4. There are six healed fractures, five in adult males and one in an adult female. No fractures are observed in the immature skeletons. Two males have Colles' fractures in their left forearms and three have spiral fractures in their lower left leg bones (Figs. 4 and 5). An adult female from the Kabira site has a healed fracture of the distal end of the left humerus (Fig. 6a). It was estimated that the epiphyseal line of the distal end of this bone had been injured at a young age due to deformity of the left elbow joint. Later, this injury was accompanied by severe secondary osteoarthritis. No fractures are observed in the clavicles or femora, which are common in archaeological skeletal remains. Although fractures of the forearm bones are common in archaeological skeletal remains and fractures to the lower long limb bones are frequent in recent human remains (Steinbock, 1976; Larsen, 1997), the frequencies of upper and lower long limb bone fractures are about the same in the Ishigaki sample. However, bone fractures are more frequent in males and on the left side in the Ishigaki sample.

\section{Osteoarthritis (Degenerative Joint Disease)}

Osteoarthritis, or degenerative joint disease (DJD), is characterized by deterioration and abrasion of the articular cartilage and new bone formation at the joint surface (Steinbock, 1976). Osteoarthritis usually occurs in the weight-bearing joints and its frequency reflects the physical activity of individuals. Several examples of degenerative joint changes, including secondary osteoarthritis, in the elbow joints of three individuals from Ishigaki are shown in Fig. 6. Osteoarthritis in the elbow joints and bodies of the lumbar vertebrae is summarized in Table 5. Elbow joint osteoarthritis tends to affect the right side of males, a finding consistent with reported cases in archaeological skeletons from North America (e.g. Bridges, 1991). Due to the small sample size, the female samples show no side differences. As would be expected given that there are no old adults represented, no severe cases of lumbar osteoarthritis are observed in these remains. Further, because severe osteoarthritis in the cervical vertebrae has been reported in other skeletal series (Bridges, 1994), additional study of the skeletal remains from Ishigaki is warranted.

\section{Periostitis and osteomyelitis}

Periostitis is a periosteal reaction that may result from infection. Extension of infection into the bone marrow results in osteomyelitis. Periostitis may be an indica- 


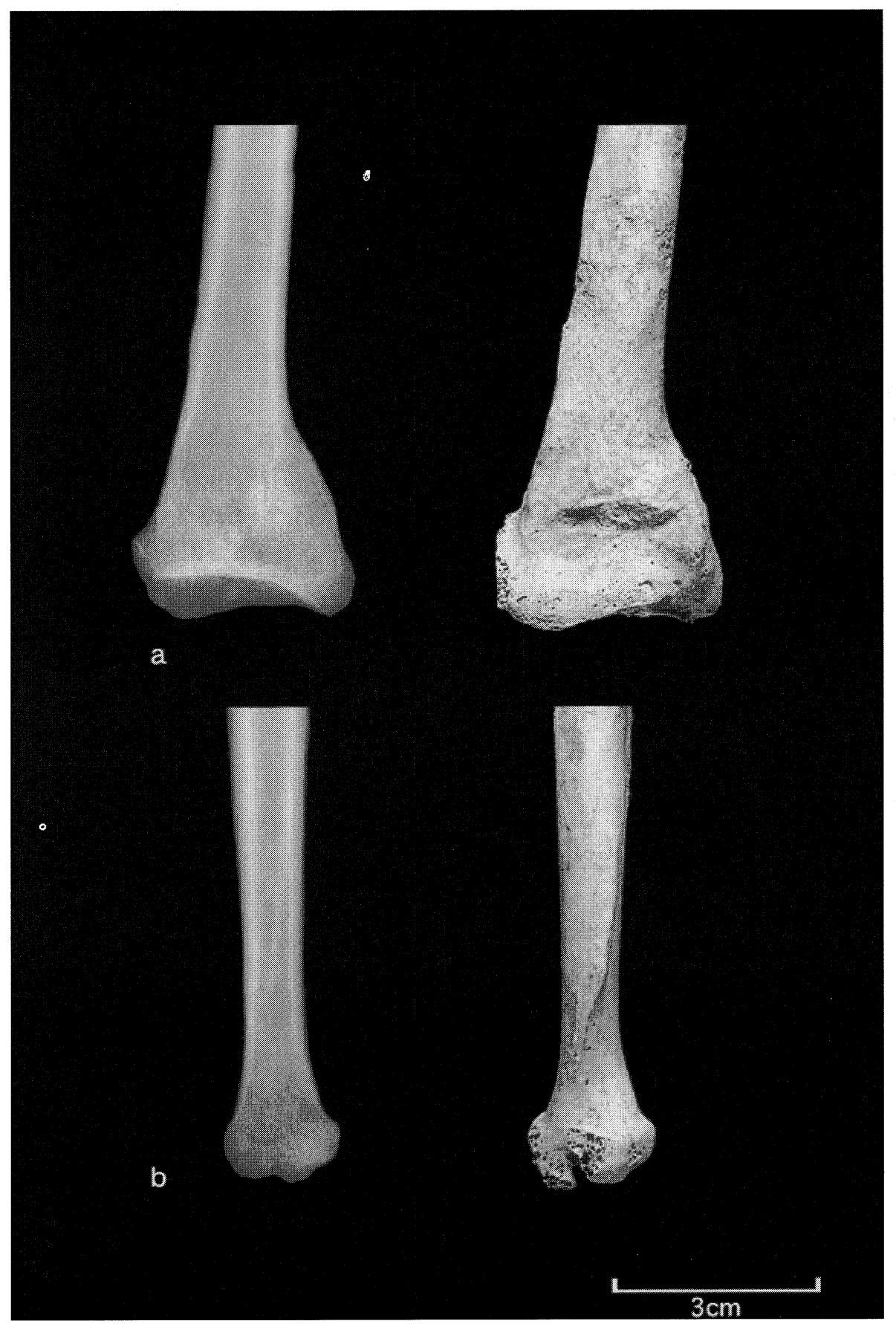

Figure 4. Photographs and radiographs of the distal ends of the left radius (a) and ulna (b). The radius exhibits a healed (Colles') fracture. The distal end of the left ulna exhibits osteoarthritis. 


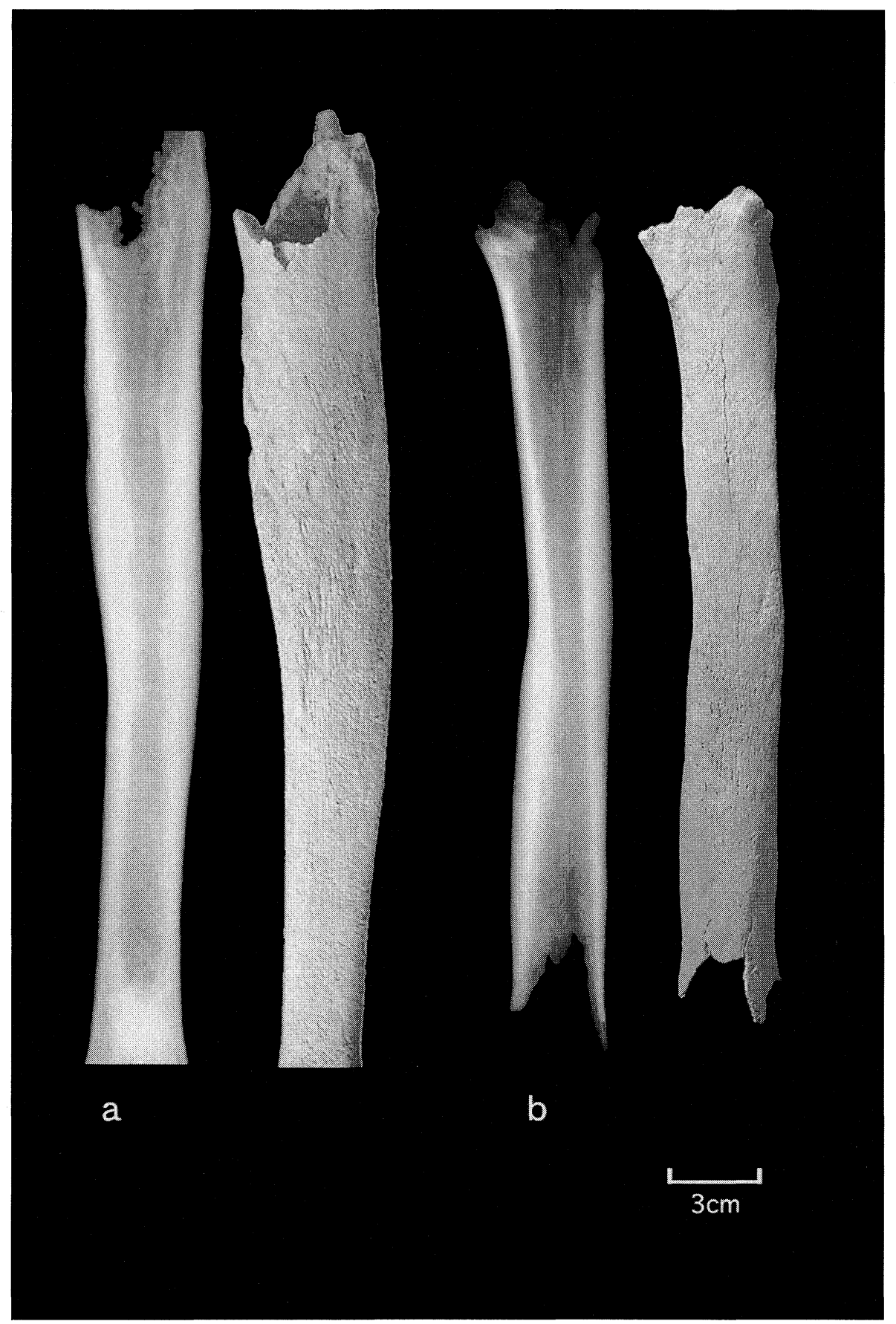

Figure 5. Spiral fractures and periostitis of the left tibiae of a mature male from the Isobe site (a) and a middle-aged male from the Kuramoto-Ato site (b). Radiographs reveal subperiosteal new bone and increased thickening of the cortex proximally. 


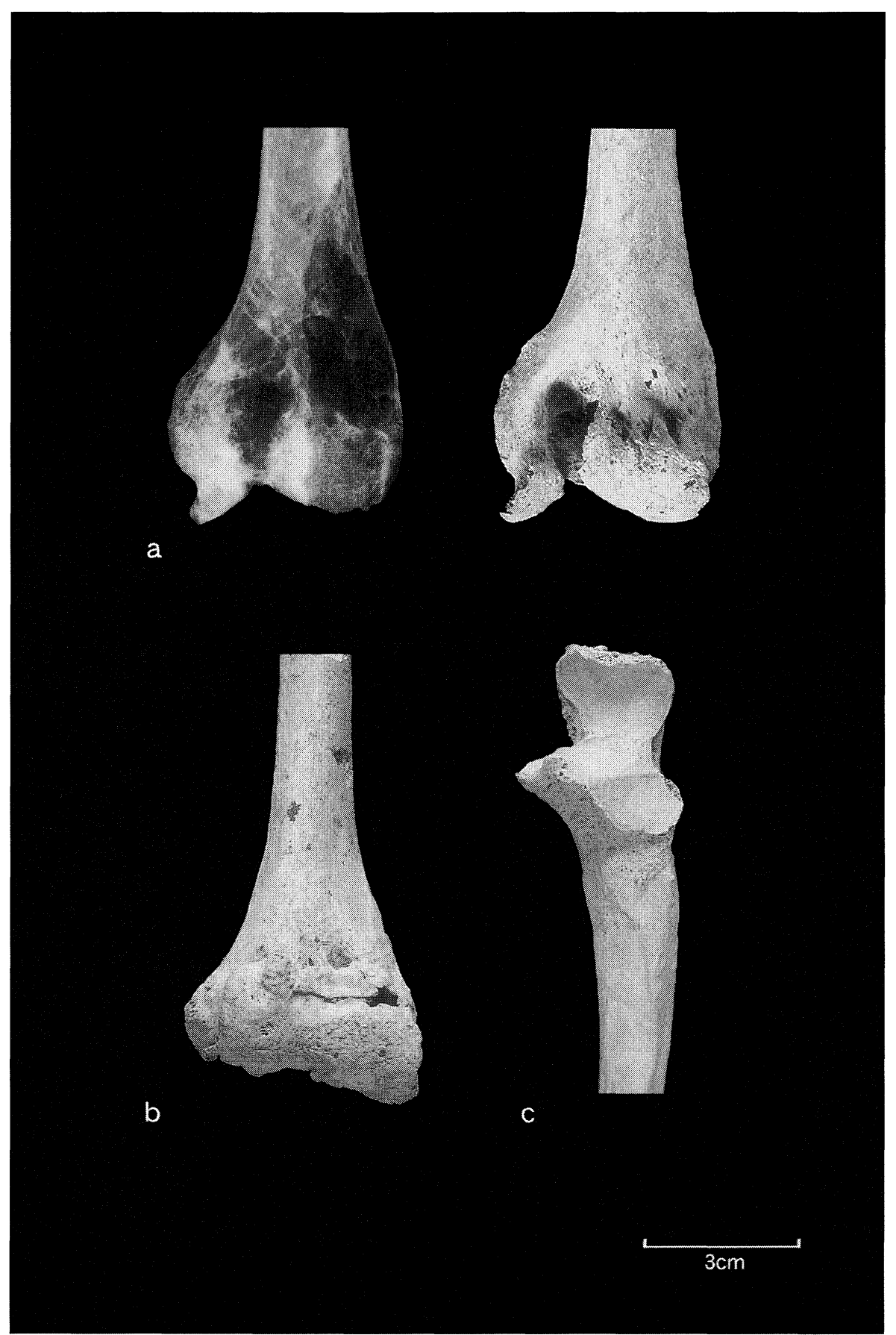

Figure 6. Marginal hyperplasia is evident in the distal ends of two humeri [an adult female (a) and an adult male (b) from the Kabira site] and the proximal ulna (c) of an adult male from the same site. A radiograph of one of the distal humeri shows osteoarthritis at the fracture site. 
Table 5. Frequencies of osteoarthritis* in the Ishigaki sample

\begin{tabular}{|c|c|c|c|c|c|c|c|c|c|c|c|}
\hline & & & \multicolumn{3}{|c|}{ Male } & \multicolumn{3}{|c|}{ Female } & \multicolumn{3}{|c|}{ Total } \\
\hline & & & $\mathrm{A}^{1}$ & $\mathrm{O}^{2}$ & $\%$ & A & $\mathrm{O}$ & $\%$ & A & $\mathrm{O}$ & $\%$ \\
\hline \multirow[t]{6}{*}{ Elbow joint } & Humerus & (R) & 2 & 6 & 33.3 & 1 & 2 & 50.0 & 3 & 8 & 37.5 \\
\hline & & (L) & 2 & 7 & 28.6 & 3 & 5 & 60.0 & 5 & 12 & 41.7 \\
\hline & Ulna & (R) & 4 & 7 & 57.1 & 0 & 2 & 0.0 & 4 & 9 & 44.4 \\
\hline & & $(\mathrm{L})$ & 2 & 9 & 22.2 & 0 & 2 & 0.0 & 2 & 11 & 18.2 \\
\hline & Radius & (R) & 2 & 5 & 40.0 & 0 & 2 & 0.0 & 2 & 7 & 28.6 \\
\hline & & (L) & 2 & 9 & 22.2 & 0 & 2 & 0.0 & 2 & 11 & 18.2 \\
\hline \multicolumn{3}{|c|}{ Body of lumbar vertebra } & 2 & 6 & 33.3 & 1 & 2 & 50.0 & 3 & 8 & 37.5 \\
\hline
\end{tabular}

${ }^{1} \mathrm{~A}=$ Affected ${ }^{2} \mathrm{O}=$ Observed.

* Any degenerative changes are counted as present using the methods of Wada (1975) and Yamaguchi (1984)

tor of chronic infection in the archaeological contexts. For example, rib periostitis has been attributed to chronic pulmonary infections including pulmonary tuberculosis (Lambert, 2002). Fig. 5 shows radiographs and photographs of the left tibiae affected by periostitis. The frequencies of periostitis and osteomyelitis in the Ishigaki sample are given in Table 6. The frequency of periostitis is higher in the lower limbs than in the upper limb bones in the Ishigaki series. Although the sex difference is not clear, periostitis is observed more frequently in the lower legs of males than in females. Non-specific periostitis of the lower limb bones, especially of the tibiae, has been reported to be common in prehistoric times (Suzuki, 1998). Suzuki (1998) reports frequencies of $11.8-20.7 \%$ in the lower limb bones of the Jomon people from various areas of Japan and $12.3 \%$ in the lower limb bones of the Early Modern Japanese from Tokyo. The frequency of periostitis is markedly higher in the Ishigaki series than in the skeletal series examined by Suzuki.

Fig. 7 shows radiographs and photographs of two cases of osteomyelitis in the adult female left tibiae. Both examples show a new bone sheath or involucrum of coarsely woven bone around the original tibial cortex and one smooth-walled canal (cloaca), for pus drainage. The inflammation of the tibia on the right is relatively localized, while that on the left exhibits a diffuse bone reaction. The two radiographs also show medullary invasions of the infection.

A specific inflammation, such as treponematosis, must be considered in the Ishigaki sample because of the extremely high frequency of periostitis and the two cases of severe osteomyelitis. Additional differential and paleopathological diagnoses will be performed in the near future.

Suzuki (1998) has reported on so-called indicators of physiological stress in prehistoric Jomon specimens from the main islands of Japan. However, except for Yamamoto's (1988) study of dental enamel hypoplasias of human remains from the Wano- 
Table 6. Frequencies of periostitis and osteomyelitis in the long limb bones

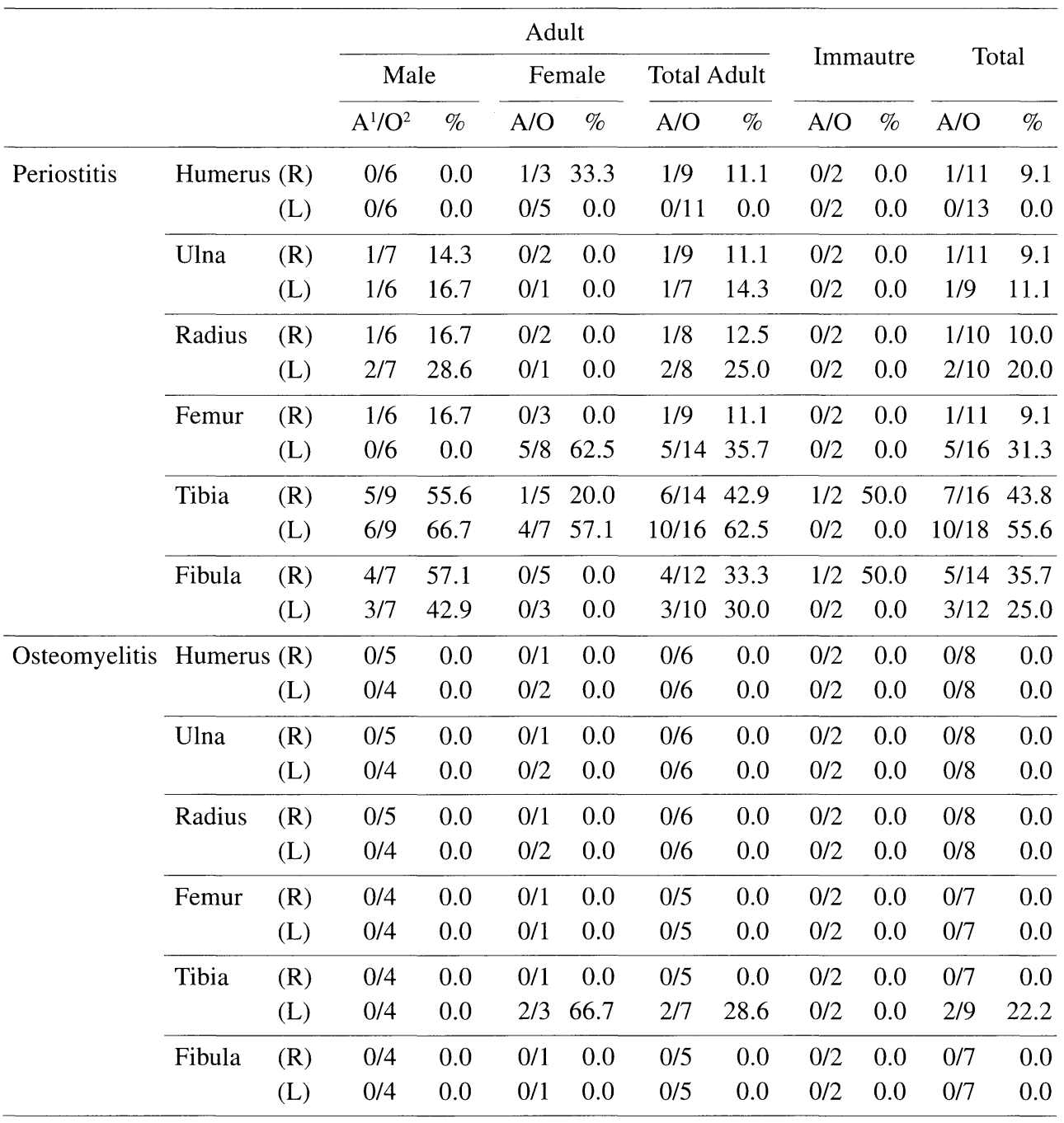

${ }^{1} \mathrm{~A}=$ Affected. $\quad{ }^{2} \mathrm{O}=$ Observed.

Tofuru-Haka site, on Amami Island, there have been few studies of similar conditions in the skeletal remains from the Ryukyu Islands. Hudson (1999) and Hudson and Takamiya (2001), however, recently reported observations of dental paleopathology for some Ryukyu Island samples, mainly from the Okinawa and Kume Islands. This latter research focused primarily on the temporal changes on subsistence economy of these earlier inhabitants.

In the present study, high frequencies for several indicators of stress are reported. The high frequencies of cribra orbitalia and dental enamel hypoplasias observed in the skeletal remains from Ishigaki Island indicate that these early inhabitants may 


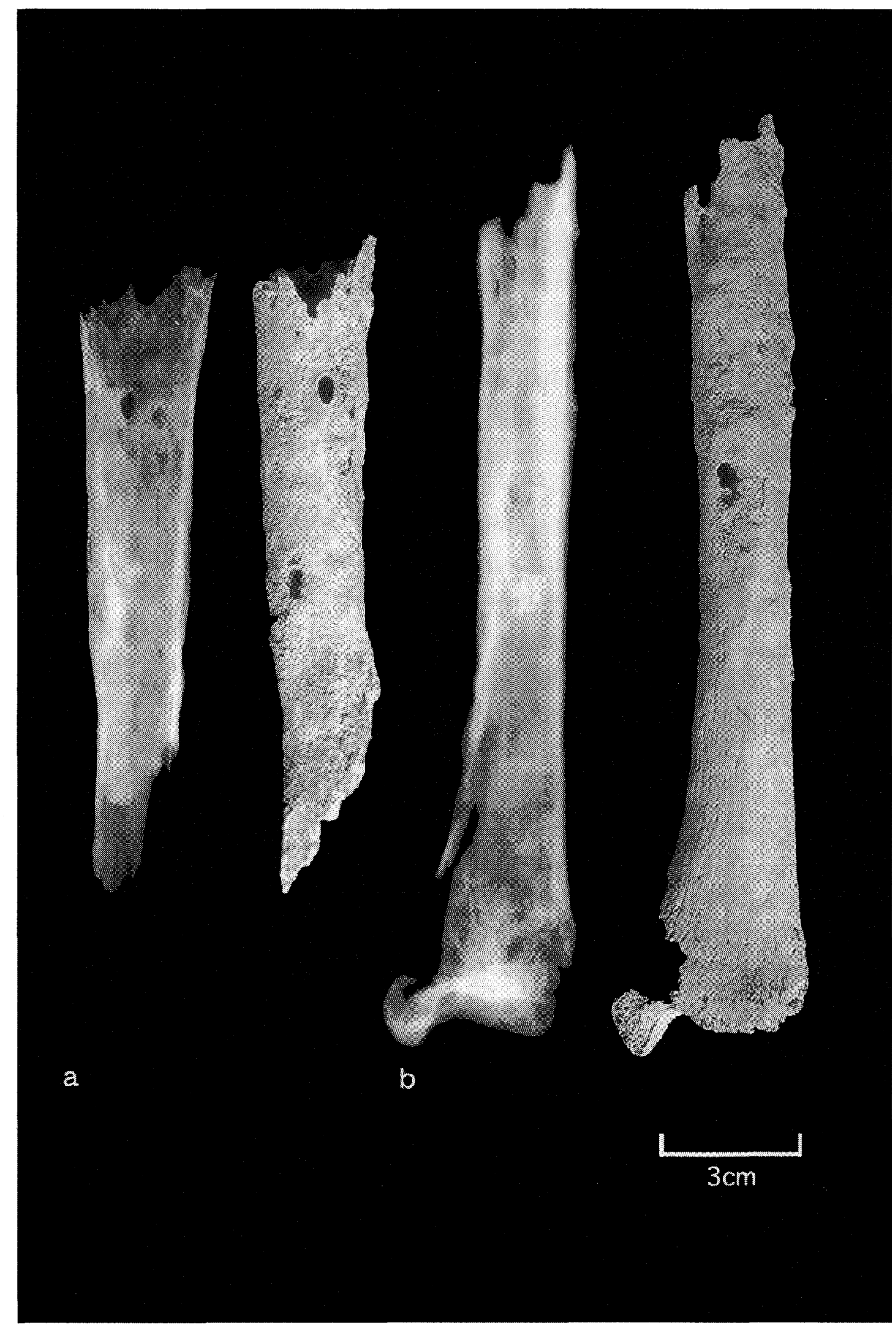

Figure 7. Osteomyelitis in the left tibiae of two adult females from the Kabira site (a, b). Some large cloacae have formed for external pus drainage. Radiographs of both tibiae show areas of destruction in the diaphysis. 
have experienced many severe nutritional deficiency stresses, infectious diseases, and/or parasitism in early childhood. Likewise, two cases of osteomyelitis and a high frequency of periostitis in the lower leg bones may be attributable to specific inflammations, suggesting that the health of these island inhabitants had been compromised.

The results of this preliminary study suggest that environmental factors may have substantially contributed to the pattern of health and disease in the medieval and early modern inhabitants of Ishigaki Island. Prior to this study, reconstructions of the way of life of the Ryukyu Islanders have been primarily based on archaeological and historical data (e.g. Asato and Harunari, 2001). Human skeletal remains offer an important independent and alternative means for addressing similar questions. Future work in bioarchaeology is expected to yield important new information on the quality of life of these ancient inhabitants.

\section{Acknowledgments}

This study was supported in part by a Grant-in-aid for Scientific Research from the Ministry of Education, Culture, Sports, Science and Technology, Japan (09208104, 10640693) and from the Japan Society for the Promotion of Science (143430274). We are deeply grateful to two anonymous reviewers for their valuable comments.

\section{References}

Asato S. and Harunari H. (eds.) (2001) The Odomarihama Shell Mound, Okinawa Prefecture, Japan: Archaeology Series No. 27. National Museum of Japanese History, Sakura. (In Japanese with English summary)

Bridges P.S. (1991) Degenerative joint disease in hunter-gatherers and agriculturalists from the southeastern United States. American Journal of Physical Anthropology, 85: 379-391.

Bridges P.S. (1994) Vertebral arthritis and physical activities in the prehistoric southeastern United States. American Journal of Physical Anthropology, 93: 83-93.

Brothwell D.R. (1981) Digging Up Bones. Cornell University Press, Ithaca, New York.

Cybulski J.S. (1977) Cribra orbitalia, a possible sign of anemia in early historic native populations of the British Columbia coast. American Journal of Physical Anthropology, 47: 31-40.

Doi N. and Hojo M. (1997) Human skeletal remains of the early modern period from the Yaeyama Kuramoto-Ato burial site. "The Bulletin of the Ishigaki City Cultural Properities," Ishigaki, 21: 129-155. (In Japanese)

Goodman A.H. and Rose J.C. (1990) Assessment of systemic physiological perturbations from dental enamel hypoplasias and associated histological structures. Yearbook of Physical Anthropology, 33: 59-110.

Fairgrieve S.I. and Molto J.E. (2000) Cribra orbitalia in two temporally disjunct population samples from the Dakhleh Oasis, Egypt. American Journal of Physical Anthropology, 111: 319-331.

Hirata K. (1988a) A contribution to the palaeopathology of cribra orbitalia in Japanese: 1. Cribra orbitalia in Edo Japanese. The St. Marianna Medical Journal, 16: 6-24.

Hirata K. (1988b) A contribution to the palaeopathology of cribra orbitalia in Japanese: 2. Secular trends in the prevalence of cribra orbitalia. The St. Marianna Medical Journal, 16: 215-229. 
Hirata K. (1990) Secular trend and age distribution of cribra orbitalia in Japanese. Human Evolution, 5: 375-385.

Hudson M. (1999) Stature and standard of living in premodern Kyushu. Journal of the Society of Human History, 11: 65-73.

Hudson M. and Takamiya H. (2001) Dental pathology and subsistence change in late prehistoric Okinawa. Bulletin of the Indo-Pacific Prehistory Association, 21: 68-79.

Kikuchi S., Ono M., Kondo O., Ohshima N., and Ishida H. (2000) Dental enamel hypoplasia of the human skeletal remains from Hokkaido. In: "The Peoples and Cultures in the Ryukyus and East Asia," Takamiya Hiroe Sensei Koki Kinen Ronshu Kankoukai, Nishihara, pp. 425-230. (In Japanese with English summary)

Knussman R. (1988) Anthropologie. Gustav Fischer Verlag, Stuttgart.

Larsen C.S. (1997) Bioarchaeology: Interpreting Behavior from the Human Skeleton. Cambridge University Press, Cambridge.

Lambert P.M. (2002) Rib lesions in a prehistoric Puebloan sample from southwestern Colorado. American Journal of Physical Anthropology, 117: 281-292.

Lukacs J.R., Walimbe S.R., and Floyd B. (2001) Epidemiology of enamel hypoplasia in deciduous teeth: Explaining variation in prevalence in western India. American Journal of Human Biology, 13: 788-807.

Miles A.E.W. (1963) Dentition in the estimation of age. Journal of Dental Research, 42: 255-263.

Naito Y. (1986) Human skeleton. "Shimotabaru Shell Mound, Ohdomarihama Shell Mound. The Bulletin of the Okinawan Cultural Properities", Naha, 74: 145. ( In Japanese)

Nakahashi T. and Nagai M. (1986) Sex assessment of fragmentary skeletal remains. Journal of the Anthropological Society of Nippon, 94: 289-305.

Nathan H. and Haas N. (1966) On the presence of cribra orbitalia in apes and monkeys. American Journal of Physical Anthropology, 24: 351-360.

Robb J., Bigazzi R., Lazzarini L., Scarsini C., and Sonego F. (2001) Social "Status" and biological "Status": A comparison of grave goods and skeletal indicators from Pontecagnano. American Journal of Physical Anthropology, 115: 213-222.

Salvadei L., Ricci F., and Manzi G. (2001) Porotic hyperostosis as a marker of health and nutritional conditions during childhood: studies at the transition between Imperial Rome and the early Middle Ages. American Journal of Human Biology, 13: 709-717.

Saunders S.R. and Keenleyside A. (1999) Enamel hypoplasia in a Canadian historic sample. American Journal of Human Biology, 11: 513-524.

Schlutz M. (2001) Paleohistopathology of bone: A new approach to the study of ancient disease. Yearbook of Physical Anthropology, 44: 106-147.

Steinbock T. (1976) Paleopathological Diagnosis and Interpretation. Bone Diseases in Ancient Human Populations. Charles C. Thomas Publisher, Springfield.

Suzuki T. (1998) Indicators of stress in prehistoric Jomon skeletal remains in Japan. Anthropological Science, 106 (Suppl.): 127-137.

Wada H. (1975) Study of changes in the vertebral bodies of Japanese with the advance of age. Sapporo Medical Journal, 44: 139-152. (In Japanese with English summary)

Yamaguchi B. (1984) Incidence of degenerative bone changes in the distal joint surfaces of the humerus and femur. Bulletin of the National Science Museum, Tokyo, Series D, 10: 9-17.

Yamamoto M. (1988) Enamel hypoplasia of the permanent teeth in Japanese from the Jomon to the Modern periods. Journal of the Anthropological Society of Nippon, 96: 417-433. (In Japanese with English summary) 
Yamamoto M. (1992) Secular trends of enamel hypoplasia in Japanese from the prehistoric to modern period. Journal of Paleopathology (Monographic Publications), 2: 231-238.

White T.D. (2000) Human Osteology, 2nd ed. Academic Press, San Diego.

Editor-in-Charge: Yuji Mizoguchi 